\title{
Effects of divalent cations on the formation of 4(5)-methylimidazole in fructose/ammonium hydroxide caramel model reaction
}

Xinlan $\mathrm{Wu},{ }^{\mathrm{a}}$ Di Yu, ${ }^{\mathrm{a}}$ Fansheng Kong, ${ }^{\mathrm{a}}$ and Shujuan $\mathrm{Yu}^{\mathrm{a}} \mathrm{b, \textrm {c } , \text { , }}$

${ }^{\text {a }}$ College of Light Industry and Food Sciences, South China University of Technology, Guangzhou 510640, China

${ }^{\mathrm{b}}$ State Key Laboratory of Pulp and paper Engineering, Guangzhou 510640, China

${ }^{\mathrm{c}}$ Guangdong Province Key Laboratory for Green Processing of Natural Products and Product Safety, Guangzhou 510640, China

*Corresponding author: Shujuan Yu; Tel.: +86 20 87113668, Fax: +86 20 87113668, E-mail:shujuanyu8@gmail.com; 
Abstract: The objective of the present study was to detail the changes of 4(5)-methylimidazole (4-MI) and its precursors in the presence of divalent cations $\left(\mathrm{Ca}^{2+}, \mathrm{Mg}^{2+}\right)$ in a fructose/ammonium hydroxide caramel model system. The content of 4-MI and its precursor methylglyoxal (MGO) was inhibited by divalent cations $\left(\mathrm{Ca}^{2+}, \mathrm{Mg}^{2+}\right)$. The possible explanation might be that fructose and its Heyns product glucosamine interact with divalent cations to form complexes and inhibit the degradation of glucosamine into MGO. Moreover, the changes of fructose, $\mathrm{NH}_{4}{ }^{+}$and brown intensity in the presence of divalent cations indicated that fructose and glucosamine underwent intra-intermolecular polymerisation into melanoidins rather than the degradation reaction into aldehydes and ketones.

Keywords: 4(5)-Methylimidazole, divalent cations, brown intensity, Maillard reaction, caramel 
Chemical compounds studied in this article

4(5)-Methylimidazole (PubChem CID: 13195);

Methylglyoxal (PubChem CID: 880);

2-Methylquinoxaline (PubChem CID: 23686); 


\section{Introduction}

Caramel colour is one of the most famous additives in the food industry. Depending on the reactants used in the manufacturing process, caramel colour was classified into four types: class I, plain caramel or caustic caramel; class II, caustic sulfite caramel; class III, ammonia caramel, and class IV, sulfite ammonia caramel (Sengar \& Sharma, 2014). 4(5)-Methylimidazole (4-MI), an unwanted byproduct in class III and class IV caramel colour, has been reported to be a carcinogenic substance in animal experiments (Chan, Hills, Kissling, \& Nyska, 2008).

Many researchers have paid attention to the content of 4-MI in food. According to recent literature, 4-MI was found in many kinds of foods, such as soft drinks, roasted coffee, curry and soy sauce (Casal, Fernandes, Oliveira, \& Ferreira, 2002; Kim, Kim, Shin, Kim, Lee, \& Kim, 2013; Yamaguchi \& Masuda, 2011). For instance, 4-MI was detected in soft drinks, ranging from 29.9 to $464 \mu \mathrm{g} / \mathrm{kg}$ (Kim, Kim, Shin, Kim, Lee, \& Kim, 2013). The office of Environmental Health Hazard Assessment (OEHHA) within the California Environmental Protection Agency recommended that the acceptable daily intake (ADI) of 4-MI should be less than $29 \mu \mathrm{g} /$ day (Office of Environmental Health Assessment, 2011). Moreover, the International Agency for Research on Cancer (IARC) classified 4-MI as a group 2B substance, a possible human carcinogen (IARC, 2012).

Many studies have focused on the formation mechanism of 4-MI in heated foods. Most probably, 4-MI results largely from the Maillard reaction between reactive carbonyl (glucose, fructose and maltose, etc) and amino acids (or ammonia compounds), proceeding through the intermediates of dicarbonyl compounds (Jang, Jiang, Hengel, \& Shibamoto, 2013). In recent years, several hypothetical formation pathways of 4-MI in the Maillard reaction have been proposed, which indicated 4-MI 
originated from the reaction of methylglyoxal (MGO), formaldehyde and ammonia (Jang, Jiang, Hengel, \& Shibamoto, 2013; Moon \& Shibamoto, 2011). Due to the toxicity and potential carcinogenity of 4-MI, efforts have been carried out to reduce its formation in foods. Several factors, such as $\mathrm{pH}$ and reactants, may influence the formation levels of 4-MI in caramel and other heated foods. For example, Lee, Jang, and Shibamoto (2013) suggested that sulfite has a significant impact on the formation of 4-MI (

Recent reports have indicated that cations can reduce acrylamide formation in thermally treated foods (Gökmen \& Şenyuva, 2007a, 2007b). Moreover, Seo et al. found that $\mathrm{Mg}^{2+}$ and $\mathrm{Fe}^{3+}$ could reduce the content of $4-\mathrm{MI}$ in a glucose $/ \mathrm{NH}_{4} \mathrm{OH}$ model system (Seo, Ka, \& Lee, 2014). However, the mechanism of how cations affect the formation of 4-MI has been ignored in recent literature. In this paper, we investigated the effects of divalent cations $\left(\mathrm{Ca}^{2+}, \mathrm{Mg}^{2+}\right)$ at different concentrations on the formation of 4-MI and its precursors in a fructose/ammonium hydroxide model system. Moreover, possible mechanism was proposed to explain the changes of 4-MI and its precursors in the presence of cations.

\section{Materials and Methods}

\subsection{Chemicals}

D-Fructose (99\%), D-glucosamine hydrochloride (99\%), 4-MI (99\%), ammonium hydroxide (25\%), $\mathrm{CaCl}_{2}(98 \%), \mathrm{MgCl}_{2} \cdot 6 \mathrm{H}_{2} \mathrm{O}$ (98\%), $\mathrm{MGO}$ (25\%), formaldehyde (25\%), o-phenylenediamine (OPD, 99\%) and 2-methylquinoxaline (2-MQ, 99\%) were purchased from Sigma-Aldrich (St. Louis, MO). Chromatographic-grade methanol was obtained from Merck (Damstadt, Germany).

Stock solutions of fructose and ammonium hydroxide were prepared at a concentration of $1 \mathrm{M}$ by dissolving $30 \mathrm{mmol}$ fructose or ammonium hydroxide in 30 
$\mathrm{mL}$ water. $\mathrm{Ca}^{2+}$ and $\mathrm{Mg}^{2+}$ were prepared at a concentration of $1 \mathrm{M}$ by dissolving 4 mmol of $\mathrm{CaCl}_{2}$ and $\mathrm{MgCl}_{2} \cdot 6 \mathrm{H}_{2} \mathrm{O}$ in $4 \mathrm{~mL}$ water, respectively.

\subsection{Preparation of model reaction mixtures}

A model system composed of fructose and ammonium hydroxide was used to study the formation of 4-MI in the presence of divalent cations $\left(\mathrm{Ca}^{2+}, \mathrm{Mg}^{2+}\right)$. Fructose solution $(1 \mathrm{M}, 400 \mu \mathrm{L})$ and ammonium hydroxide solution $(1 \mathrm{M})$ were combined in a 10-mL screw-cap tube. Varying amounts of each cation were added into the reaction mixture. Total reaction volume was adjusted to $4 \mathrm{~mL}$ with water in each case. The final concentrations of each cation were $0,5,20,50,100,200 \mathrm{mM}$, respectively. The $\mathrm{pH}$ value of the reaction mixture was measured as 10.23 before the addition of cations. Adding up to $200 \mathrm{mM}$ of cations into the reaction mixture did not change the $\mathrm{pH}$ value significantly. The mixtures were heated in an oil bath at $120^{\circ} \mathrm{C}$ for $30 \mathrm{~min}$. After heating, samples were taken and immediately cooled in iced water. Subsequently, $200 \mu \mathrm{L}$ sample were mixed with $800 \mu \mathrm{L}$ OPD solution $(1 \mathrm{mg} / \mathrm{mL}$ in $1 \mathrm{M}$ PBS of $\mathrm{pH} 7.4$ ), and then incubated at room temperature for $12 \mathrm{~h}$. The remainder of sample was stored at $4{ }^{\circ} \mathrm{C}$ for further analyses.

A mixture of MGO $(0.4 \mathrm{mmol})$, formaldehyde $(0.4 \mathrm{mmol})$ and ammonium hydroxide $(0.4 \mathrm{mmol})$ was dissolved in distilled water, with the addition of water (as a control), $\mathrm{Ca}^{2+}$ or $\mathrm{Mg}^{2+}(100 \mathrm{mM}$, final concentration). Total reaction volume was adjusted to $4 \mathrm{~mL}$ with water in each case. The mixtures were heated at $120{ }^{\circ} \mathrm{C}$ for 10 min and then immediately cooled in iced water. All samples were stored at $4{ }^{\circ} \mathrm{C}$ until used.

\subsection{HPLC-MS/MS analysis of 4-MI}

The model reaction samples were pre-treated referring to the literature with a minor modification (Wu, Huang, Yu, \& Kong, 2016). Briefly, $3 \mathrm{~mL}$ sample were passed 
through an Ansys SPEC SCX Disc $15 \mathrm{mg} / 3 \mathrm{~mL}$ cartridge (Varian, Walnut Creek, CA) after the addition of $3 \mathrm{~mL}$ of $0.1 \mathrm{~N} \mathrm{HCl}$, and then the cartridge was washed with $3 \mathrm{~mL}$ methanol. The retained compounds in the cartridge were eluted with $6 \mathrm{~mL}$ of methanol/ammonia $(5 \%, v / v)$. The collected extracts were dried using a rotary evaporator at $40{ }^{\circ} \mathrm{C}$; then the residues were dissolved with $3 \mathrm{~mL}$ deionized water for 4-MI analysis. The quantification of 4-MI was performed using an HPLC-MS/MS system as reported in the literature (Wu, Huang, Yu, \& Kong, 2016). The HPLC-MS/MS system consisted of a Waters HPLC system (Waters Co., Milford, MA), coupled to a Thermo Scientific (San Jose, CA) LTQ mass spectrometer equipped with an electrospray ionisation (ESI) interface. The chromatographic separation was performed on a Waters XBridge BEH Shield RP18 Column $(3.5 \mu \mathrm{m}$, $3.0 \mathrm{~mm} \times 150 \mathrm{~mm})$ using mobile phase $\mathbf{A}(10 \mathrm{mM}$ of ammonia in high-purity water $)$ and mobile phase $\mathbf{B}$ (methanol) in a gradient program: 0-10 min: 5\% $\mathbf{B} ; 11-15 \mathrm{~min}$ : 5\% $\mathbf{B}$ to $100 \% \mathbf{B} ; 15-20 \mathrm{~min}: 100 \% \mathbf{B}$. The flow rate was $0.3 \mathrm{~mL} / \mathrm{min}$ and the column temperature was $25{ }^{\circ} \mathrm{C}$. In the mass spectrometer, the positive ion mode of ESI was used at a capillary temperature of $275{ }^{\circ} \mathrm{C}$ with nitrogen gas (35 psi). The selected reaction monitoring (SRM) mode was used and the collision energy was set at $33 \mathrm{~V}$. The signal of $m / z 56$ was used for 4-MI quantification.

\subsection{HPLC-UV analysis of MGO with its quinoxaline form}

As MGO can not be measured directly, it was measured using the corresponding quinoxalines 2-MQ. After derivatisation with OPD, sample was filtered through 0.45- $\mu \mathrm{m}$ Millex-HN nylon filters (Millipore, Billerica, MA) and analyzed by a Waters HPLC system, which consisted of a Waters 600 pump, a Rheodyne $7725 \mathrm{i}$ manual injector and a Waters 2998 DAD. The injection volume was $20 \mu \mathrm{L}$ and the chromatographic separation was carried out on a Waters XBridge BEH Shield RP18 
Column $(3.5 \mu \mathrm{m}, 3.0 \mathrm{~mm} \times 150 \mathrm{~mm})$ using a gradient program (water/methanol system) at a flow rate of $1.0 \mathrm{~mL} / \mathrm{min}$ : a linear gradient of $5 \%$ methanol to $20 \%$ methanol, from 0 to10 min, then a linear gradient of $20 \%$ methanol to $30 \%$ methanol, from 10 to $28 \mathrm{~min}$, and a linear gradient of $30 \%$ methanol to $100 \%$ methanol, from 28 to $36 \mathrm{~min}$, and at last, $100 \%$ methanol from 36 to $45 \mathrm{~min}$. The detection wavelength was set at $315 \mathrm{~nm}$ and column temperature was set at $25^{\circ} \mathrm{C}$.

\subsection{Reducing sugars measurement}

Reducing sugars were determined by HPLC according to the method published in the literature (Guan, Yu, Yu, Xu, Shi, \& Sun, 2011). HPLC analysis was carried out using a Waters 600 pump, a Rheodyne 7725i manual injector, equipped with Waters 414 refractive index detector (RID). The sample was diluted 20-fold with distilled water, filtered through $0.45-\mu \mathrm{m}$ Millex-HN nylon filters and then analysed using the HPLC-RID system. The separation was performed using a Sugar-pak1 $6.5 \times 300 \mathrm{~mm}$ ion exchange column (Waters) operated at $90{ }^{\circ} \mathrm{C}$. The injection volume was $20 \mu \mathrm{L}$, and the mobile phase was a $50 \mathrm{mg} / \mathrm{L}$ EDTA-Ca aqueous solution delivered at a flow rate of $0.5 \mathrm{~mL} / \mathrm{min}$. The chromatography run time was $30 \mathrm{~min}$.

\section{6 $\mathrm{NH}_{4}{ }^{+}$analysis}

High-performance anion exchange chromatography (HPAEC) was used for determination of $\mathrm{NH}_{4}{ }^{+}$. The samples were filtered through $0.45-\mu \mathrm{m}$ Millex-HN nylon filters and then analysed by a DX 5000 ion chromatography system (Dionex Co., Sunnyvale, CA) composed of a gradient pump (model EG40) and a conductivity detector. The anion self-regenerating suppressor (CSAS 300, $4 \mathrm{~mm}$ ) was working in the autosuppression recycle mode. The injection volume was $25 \mu \mathrm{L}$. Analytical separation was accomplished on a CS12A cation exchange column $(250 \times 4 \mathrm{~mm}$, 
Dionex $)$ and a CS12A guard column $(50 \times 4 \mathrm{~mm}$, Dionex $)$ using isocratic elution of $20 \mathrm{mmol} / \mathrm{L}$ methanesulfonic acid at a flow rate of $1.0 \mathrm{~mL} / \mathrm{min}$ at $30^{\circ} \mathrm{C}$ for $20 \mathrm{~min}$.

\subsection{Measurement of browning intensity}

The browning intensity of model reaction samples was measured according to the literature with a slight modification (Guan, Yu, Yu, Xu, Shi, \& Sun, 2011). The treated solution was diluted 20 -fold using distilled water and the absorbance was measured at $420 \mathrm{~nm}$ using a UV-1810 spectrophotometer (Puxi, Beijing, China).

\subsection{Thermal Treatment of Glucosamine}

Glucosamine $(0.04 \mathrm{mmol})$ was dissolved in deionised water. The solution $\mathrm{pH}$ value was adjusted to $10.23 \pm 0.05$ using $\mathrm{NaOH}$ solution $(1 \mathrm{M})$. Then, $\mathrm{Ca}^{2+}$ or $\mathrm{Mg}^{2+}$ (100 mM, final concentration) was added to the mixture. The control sample used water to replace cations. The total mixture volume was filled up to $4 \mathrm{~mL}$ with water. The mixture was heated at $120{ }^{\circ} \mathrm{C}$ for $30 \mathrm{~min}$ and then immediately cooled in iced water. Subsequently, $200 \mu \mathrm{L}$ sample were mixed with $800 \mu \mathrm{L}$ OPD solution (1 $\mathrm{mg} / \mathrm{mL}$ in $1 \mathrm{M}$ PBS, $\mathrm{pH}$ 7.4), and then incubated at room temperature for $12 \mathrm{~h}$. After that, the MGO as its derivative was detected using HPLC-UV, and the residual glucosamine was detected using HPAEC.

\subsection{Analysis of glucosamine derived from glucosamine-cation degradation}

The samples were filtered through $0.45-\mu \mathrm{m}$ Millex-HN nylon filters, then analysed on a Dionex DX 5000 system, composed of a gradient pump (model EG40) with on-line degassing, and an ECD (model ED40). Separation was accomplished on a CarboPac PA1 anion-exchange column $(250 \times 4 \mathrm{~mm}$; Dionex $)$ and a CarboPac PA1 guard column $(50 \times 4 \mathrm{~mm}$; Dionex) using mobile phase $\mathbf{A}$ (water) and mobile phase $\mathbf{B}$ ( $\mathrm{NaOH}$ solution, $500 \mathrm{mM}$ ) in a gradient program with a flow of $1 \mathrm{~mL} / \mathrm{min}$ : $0-18 \mathrm{~min}$, 
$5 \% \mathbf{B} ; 18-20 \mathrm{~min}, 5 \% \mathbf{B}$ to $100 \% \mathbf{B} ; 20-30 \mathrm{~min}, 100 \% \mathbf{B}$. The injection volume was $25 \mu \mathrm{L}$.

\subsection{Statistical analyses}

All experiments were carried out in at least triplicate. Means and standard errors of data were calculated for each treatment. Analysis of variance (ANOVA) was carried out using SAS 9.3 software (SAS Institute Inc., Cary, NC) to determine any significant differences between treatments $(p<0.05)$.

\section{Results}

\subsection{Changes in fructose/ammonium hydroxide system}

Effects of divalent cations were evaluated in a caramel model system containing fructose/ammonium hydroxide. $\mathrm{Ca}^{2+}$ and $\mathrm{Mg}^{2+}$ were chosen because they have little effect on the $\mathrm{pH}$ of the model system. Other divalent cations, such as $\mathrm{Cu}^{2+}, \mathrm{Fe}^{2+}, \mathrm{Zn}^{2+}$, change the $\mathrm{pH}$ significantly and were not considered in this study. Figure 1 (A) shows the results of 4-MI analysis in the samples of fructose/ammonium hydroxide model system. Obviously, the content of 4-MI was significantly reduced along with the increase concentration of cations. The results were in agreement with Seo et al. who found that the addition of magnesium sulfate can reduce the amount of 4-MI in glucose/ammonium hydroxide system (Seo, Ka, \& Lee, 2014).

As the primary precursor of 4-MI, MGO was detected in this paper. MGO should undergo derivatization into quinoxaline adduct before HPLC analyses (Degen, Hellwig, \& Henle, 2012; Mavric, Wittmann, Barth, \& Henle, 2008; W. Wang, Yagiz, Buran, do Nascimento Nunes, \& Gu, 2011). In order to investigate whether the divalent cations influence the derivatisation process, a standard sample of MGO was derived with the addition of $100 \mathrm{mM} \mathrm{Ca}^{2+}$ and $\mathrm{Mg}^{2+}$, respectively. Results showed 
that the divalent cations had no effect on the derivatisation process (data no shown). The results of MGO detection are shown in Figure 1 (B). It was observed that MGO decreased as the concentration of cations increased. The variation trend of MGO was in accordance with 4-MI, which indicated that the decrease of 4-MI was related to the reduction of MGO.

As the reaction precursors, the decomposition rate of fructose and the consumption rate of $\mathrm{NH}_{4}^{+}$may also affected by the addition of cations. Under heat, fructose may convert into glucose and other hexoses. In fact, it was observed that fructose was changed to glucose and mannose in the present study. Therefore, the residual total reducing sugars were used to represent the decomposition rate of fructose in this paper. The content of residual reducing sugars and $\mathrm{NH}_{4}{ }^{+}$are shown in Figure 2 (A) and (B), respectively. Interestingly, when low concentration of cation (5 or $20 \mathrm{mM}$ ) was added, the residual reducing sugars of the reaction were increased. However, a significant decrease of residual reducing sugars was observed when the additive concentration of cation increased to 50,100 and $200 \mathrm{mM}$, indicating that the decomposition rate of reducing sugars increased at a high concentration of cation. Conversely, the residual $\mathrm{NH}_{4}{ }^{+}$was increased along with the increased concentration of cation, which meant that the consumption rate of $\mathrm{NH}_{4}{ }^{+}$decreased in the presence of cation. Similar results were obtained in a glucose/asparagine system by Gökmen and Şenyuva, who found that glucose decomposed more rapidly in the presence of cations during heating, while the rate of asparagine decomposition decreased at the same time (Gökmen \& Şenyuva, 2007b).

Browning intensity (A420) is often used as an indicator of the extent to which the Maillard reaction takes place in foods and symbolises an advanced stage of the Maillard reaction. Thus, detecting A420 is important to understand the variation in 
Maillard reaction. As shown in Figure 3, A420 decreased at low concentrations of cation, whereas, A420 increased significantly at high level of cation, compared to the control. Interestingly, the variation of A420 was consistent with the variation of fructose decomposition rate. The results indicated that the value of A420 is primarily related to the fructose decomposition. The increase of A420 in the presence of cation was also reported in the literature; $\mathrm{Ca}^{2+}$ and $\mathrm{Mg}^{2+}$ could increase the browning intensity in a xylose/glycine system (Rizzi, 2008).

\subsection{Changes in glucosamine thermal system}

To better understand the change in the initial stage of the Maillard reaction, changes in Heyns product should be clearly studied. As the Heyns product of the fructose/ammonium hydroxide system, glucosamine was heated with or without cation under basic conditions $(\mathrm{pH} 10.2)$ in this study. As shown in Figure 4 (A), the content of glucosamine was decreased when $100 \mathrm{mM}$ divalent cation was added into the reaction mixture, which meant that the addition of cations accelerate the decomposition of glucosamine.

In the Maillard reaction, the main way to produce MGO is through the degradation of glucosamine, according to the literature (Wang \& Ho, 2012). MGO derived from glucosamine degradation was analysed and the results are shown in Figure 4 (B). The addition of $100 \mathrm{mM}$ divalent cation led to a significant decrease of MGO. This variation of MGO was in accordance with the results in the fructose/ammonium hydroxide system, indicating that the decreased content of MGO in the fructose/ammonium hydroxide system was because the cations inhibit the degradation of glucosamine into MGO.

A420 was also measured in glucosamine heated system in the presence of cations. As shown in Figure $4(\mathrm{C})$, the addition of cations increased the A420 value, which 
indicated that the divalent cations can accelerate the polymerisation reaction in the process of glucosamine degradation. This result was in agreement with the changes of A420 value in the fructose/ammonium hydroxide system with the addition of cations.

\section{Discussion}

Recent literature has focused on using cations to reduce the content of acrylamide formed in the Maillard reaction. Gökmen and Şenyuva found that acrylamide was reduced in the presence of $\mathrm{Ca}^{2+}$ in a glucose/asparagine system. Meanwhile, the formation of the Schiff base of asparagine, the key intermediate leading to acrylamide, was prevented by the cations (Gökmen \& Şenyuva, 2007a). It is known that metal ions can form complexes with Maillard reaction products (Nashalian \& Yaylayan, 2014; Ramonaityte, Kersience, Adams, Tehrani, \& De Kimpe, 2009). These complexes may be the main reason for the inhibition of the formation of Schiff base in the previous study of Gökmen and Şenyuva (2007a). On the basis of the previous studies and the present results, the mechanism of 4-MI inhibition by divalent cations is proposed in Figure 5 (Gökmen \& Şenyuva, 2007a; Nashalian \& Yaylayan, 2014; Nuttall \& Stalker, 1977; Ramonaityte, Kersience, Adams, Tehrani, \& De Kimpe, 2009). It can be seen that the formation of MGO was inhibited by the complexes formed by glucosamine and cations. Furthermore, in order to investigate if divalent cations influence the precursors of 4-MI, a system containing MGO, formaldehyde and ammonium hydroxide with or without cation was prepared (as described in section 2.2). As shown in Figure 6, 4-MI was slightly reduced in the presence of divalent cation. Thus, MGO may also interact with divalent cation to form a complex and inhibit 4-MI formation (as proposed in Figure 5).

It can be known from Figure 5 that the degradation of fructose and glucosamine was inhibited by divalent cations. In this case, the content of residual fructose and 
glucosamine should increase in the presence of divalent cations (especially high concentration of divalent cations). However, the residual fructose and glucosamine were decreased when adding high content of divalent cation (Figure 2 (A) and 4 (A)). Similar results were also found by Gökmen and Şenyuva (2007b), who reported that the rate of glucose decomposition increased when adding cations to a glucose/asparagine system. They attributed glucose loss to the increased content of hydroxymethylfurfural. However, hydroxymethylfurfural can only form under acidic or neutral conditions. Naturally, no hydroxymethylfurfural was found in the fructose/ammonium hydroxide system (basic conditions). Comparing the changes of fructose and glucosamine (Figures 2 (A) and 4 (A)) with the corresponding A420 value (Figures 3 and $4(\mathrm{C})$ ), it can be seen that the variation of fructose or glucosamine was reversed to A420 value, which indicate that the increase of A420 was related to the consumption of fructose and glucosamine. A possible explanation could be that divalent cation promotes melanoidin formation from fructose and glucosamine. As a result, the residual fructose and glucosamine decreased, while A420 increased at the same time. Furthermore, the increase of $\mathrm{NH}_{4}^{+}$(which is relative to the control with no cations) also indicated that fructose and glucosamine underwent intra-intermolecular polymerisation into melanoidins rather than the degradation reaction into aldehydes and ketones. However, more experiments are needed to prove this hypothesis.

Based on the above hypothesis, the phenomenon that A420 decreased at low concentration of divalent cations (Figure 3) can be explained as follows. When the cation concentration is low, almost all of the divalent cations are incorporated into complexes. In this case, no free divalent cation can be used to catalyse the fructose 
and glucosamine into pigments. As a result, the residual fructose was increased when adding low concentration of divalent cations, as shown in Figure 2 (A).

In summary, the content of 4-MI can be reduced by divalent cations in a fructose/ammonium hydroxide caramel model system. In addition, the colour intensity was accelerated in the presence of divalent cations. Thus, divalent cations can be applied to obtain caramel with a low content of 4-MI as well as high colour intensity.

\section{Acknowledgements}

All authors acknowledge the national science foundation of China (Grant No.31271889 and Grant No.31071564), and the Science and Technology Planning Project of Guangdong Province, China(No.2014B020205001 and No.2013J4500036).

\section{Reference}

Casal, S., Fernandes, J. O., Oliveira, M., \& Ferreira, M. A. (2002). Gas chromatographic-mass spectrometric quantification of 4-(5-)-methylimidazole in roasted coffee after ion-pair extraction. Journal of Chromatography A, 976(1-2), 285-291.

Chan, P., Hills, G., Kissling, G., \& Nyska, A. (2008). Toxicity and carcinogenicity studies of 4-methylimidazole in F344/N rats and B6C3F1 mice. Archives of toxicology, 82(1), 45-53.

Degen, J., Hellwig, M., \& Henle, T. (2012). 1, 2-Dicarbonyl compounds in commonly consumed foods. Journal of Agricultural and Food Chemistry, 60(28), 7071-7079. 
Goekmen, V., \& Senyuva, H. Z. (2007a). Acrylamide formation is prevented by divalent cations during the Maillard reaction. Food Chemistry, 103(1), 196-203.

Goekmen, V., \& Senyuva, H. Z. (2007b). Effects of some cations on the formation of acrylamide and furfurals in glucose-asparagine model system. European Food Research and Technology, 225(5-6), 815-820.

Guan, Y.-G., Yu, P., Yu, S.-J., Xu, X.-B., Shi, W.-H., \& Sun, W.-W. (2011). Effects of pressure on the glucose-ammonium sulphite caramel solutions. Food Chemistry, 127(2), 596-601.

IARC Monographs. 4-Methylimidazole. URL Monographs.iarc.fr/ENG/ Monographs/ vol101/mono101-015.pdf (accessed Oct 16, 2012)

Jang, H. W., Jiang, Y., Hengel, M., \& Shibamoto, T. (2013). Formation of 4(5)-Methylimidazole and Its Precursors, alpha-Dicarbonyl Compounds, in Maillard Model Systems. Journal of Agricultural and Food Chemistry, 61(28), 6865-6872.

Kim, T. R., Kim, S. U., Shin, Y., Kim, J. Y., Lee, S. M., \& Kim, J. H. (2013). Determination of 4-Methylimidazole and 2-Acetyl-4(5)tetrahydroxybutylimidazole in Caramel Color and Processed Foods by LC-MS/MS. Preventive Nutrition and Food Science, 18(4), 263-268.

Lee, K.-G., Jang, H., \& Shibamoto, T. (2013). Formation of carcinogenic 4(5)-methylimidazole in caramel model systems: A role of sulphite. Food Chemistry, 136(3-4), 1165-1168.

Mavric, E., Wittmann, S., Barth, G., \& Henle, T. (2008). Identification and quantification of methylglyoxal as the dominant antibacterial constituent of 
Manuka (Leptospermum scoparium) honeys from New Zealand. Molecular Nutrition and Food Research, 52(4), 483-489.

Moon, J.-K., \& Shibamoto, T. (2011). Formation of Carcinogenic 4(5)-Methylimidazole in Maillard Reaction Systems. Journal of Agricultural and Food Chemistry, 59(2), 615-618.

Nashalian, O., \& Yaylayan, V. A. (2014). Thermally induced oxidative decarboxylation of copper complexes of amino acids and formation of Strecker aldehyde. Journal of Agricultural and Food Chemistry, 62(33), $8518-8523$.

Nuttall, R. H., \& Stalker, D. M. (1977). Structure and bonding in the metal complexes of ethylenediaminetetra-acetic acid. Talanta, 24(6), 355-360.

Office of Environmental Health Assessment. Notice of intent to list 4-methylimidazole, 2011. URL http://oehha.ca.gov/prop65/crnr_notices/ admin_listing/intent_to_list/noilpkg32.html.

Ramonaityte, D. T., Kersience, M., Adams, A., Tehrani, K. A., \& De Kimpe, N. (2009). The interaction of metal ions with Maillard reaction products in a lactose-glycine model system. Food Research International, 42(3), 331-336.

Rizzi, G. P. (2008). Effects of cationic species on visual color formation in model Maillard reactions of pentose sugars and amino acids. Journal of Agricultural and Food Chemistry, 56(16), 7160-7164.

Sengar, G., \& Sharma, H. K. (2014). Food caramels: a review. Journal of Food Science and Technology, 51(9), 1686-1696. 
Seo, S., Ka, M.-H., \& Lee, K.-G. (2014). Reduction of Carcinogenic 4(5)-Methylimidazole in a Caramel Model System: Influence of Food Additives. Journal of Agricultural and Food Chemistry, 62(27), 6481-6486.

Wang, W., Yagiz, Y., Buran, T. J., do Nascimento Nunes, C., \& Gu, L. (2011). Phytochemicals from berries and grapes inhibited the formation of advanced glycation end-products by scavenging reactive carbonyls. Food Research International, 44(9), 2666-2673.

Wang, Y., \& Ho, C.-T. (2012). Flavour chemistry of methylglyoxal and glyoxal. Chemical Society Reviews, 41(11), 4140-4149.

Wu, X., Huang, M., Yu, S., \& Kong, F. (2016). Rapid and quantitative detection of 4 (5)-methylimidazole in caramel colours: A novel fluorescent-based immunochromatographic assay. Food Chemistry, 190, 843-847.

Yamaguchi, H., \& Masuda, T. (2011). Determination of 4(5)-Methylimidazole in Soy Sauce and Other Foods by LC-MS/MS after Solid-Phase Extraction. Journal of Agricultural and Food Chemistry, 59(18), 9770-9775. 


\section{Figure Legends:}

Figure 1. Content of 4-MI (A) and MGO (B) formed in fructose/ammonium hydroxide model system.

Figure 2. Residual reducing sugars (A) and $\mathrm{NH}_{4}^{+}$(B) in fructose/ammonium hydroxide model system.

Figure 3. Changes of A420 in fructose/ammonium hydroxide model system.

Figure 4. Changes of residual glucosamine (A), MGO (B) and A420 (C) in glucosamine-cation system.

Figure 5. Proposed formation pathway of 4-MI in the presence of divalent. ' $\mathrm{M}^{2+}$ 'means $\mathrm{Ca}^{2+}$ or $\mathrm{Mg}^{2+}$.

Figure 6. Content of 4-MI formed in $\mathrm{MGO}$ /formaldehyde/ammonium hydroxide model system. 

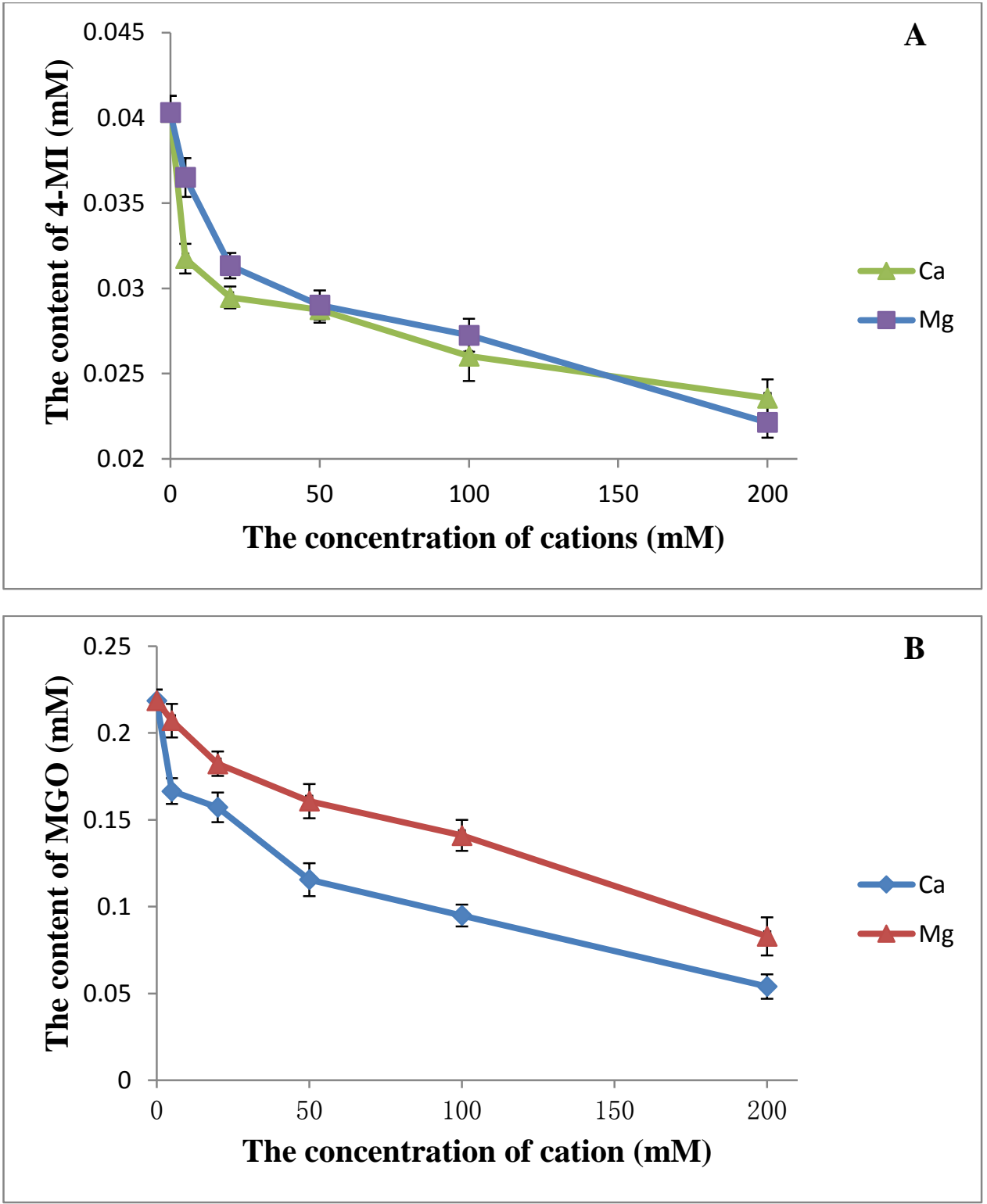

Figure 1 

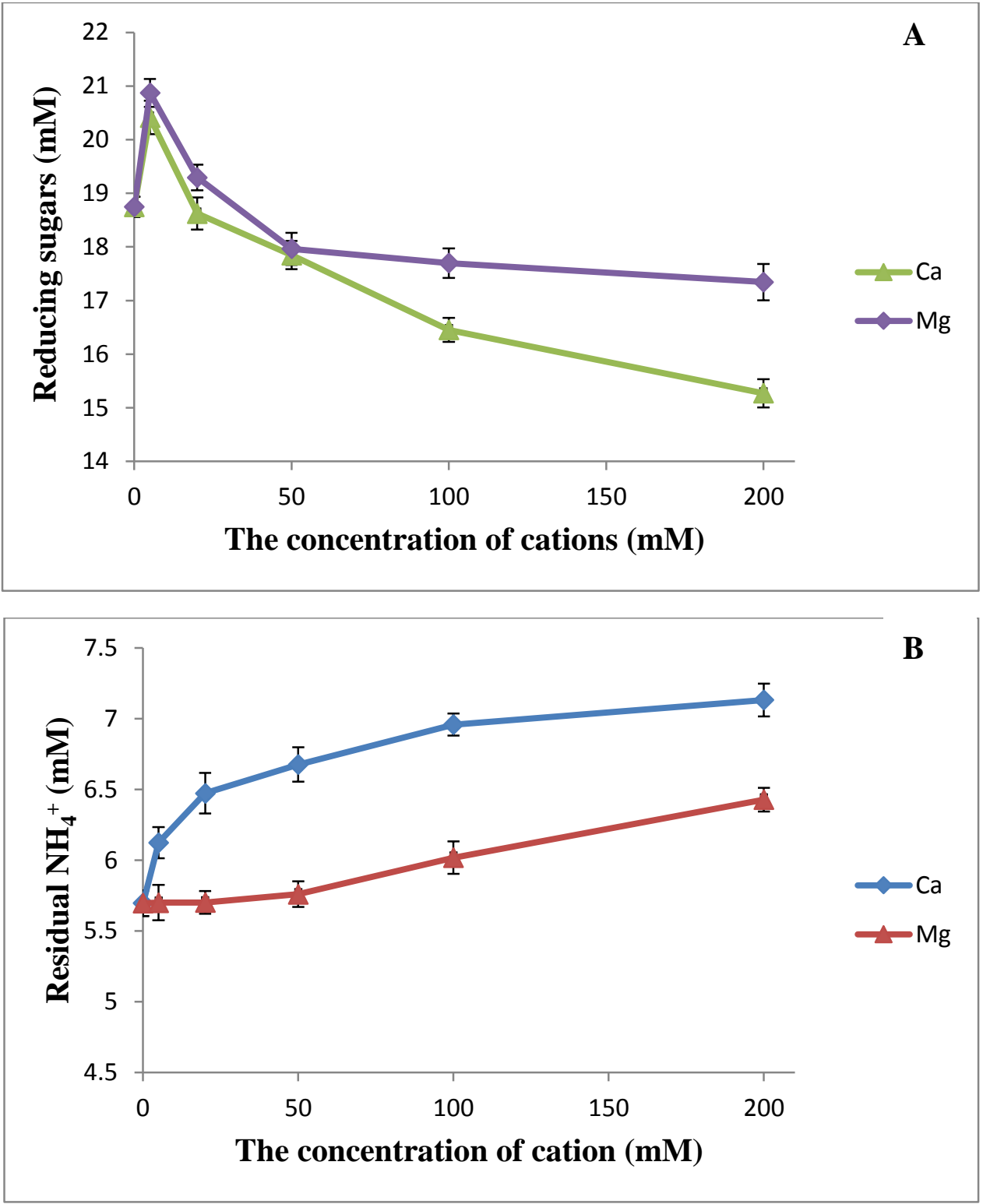

Figure 2 


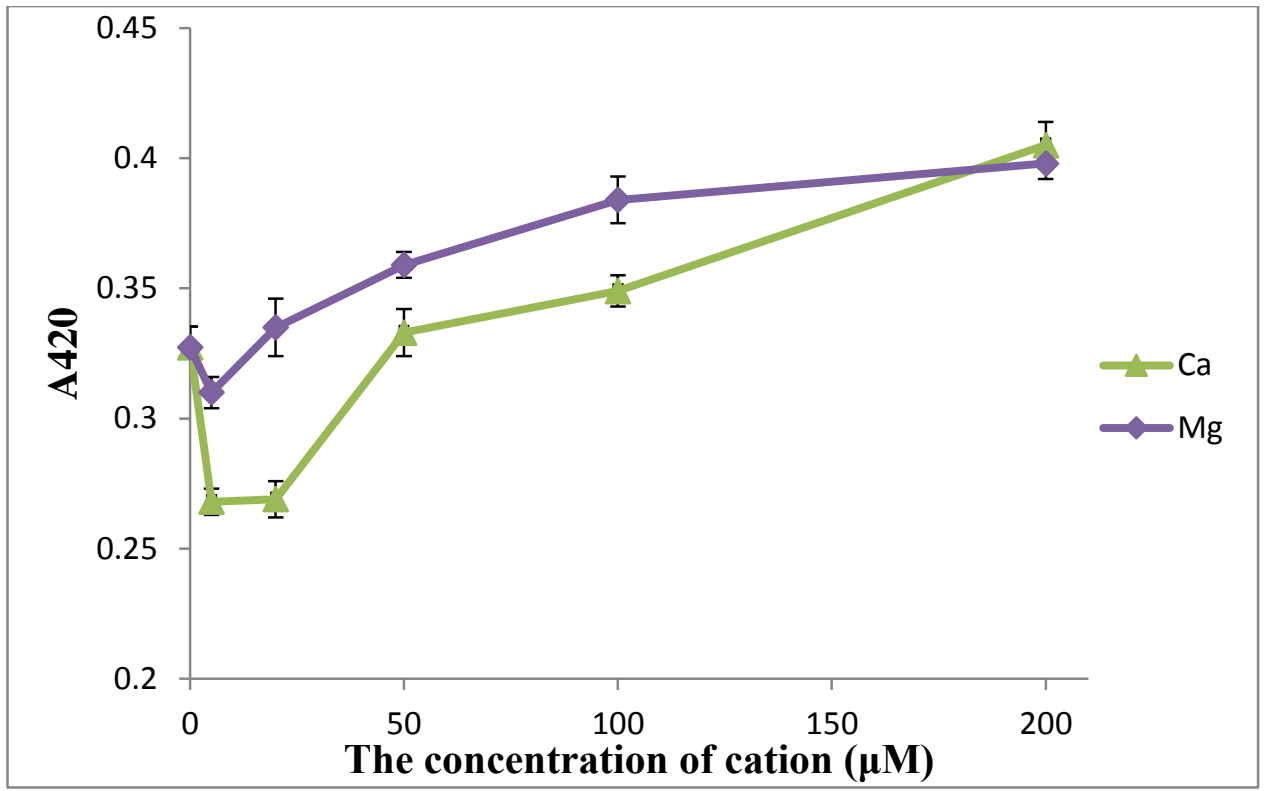

Figure 3 

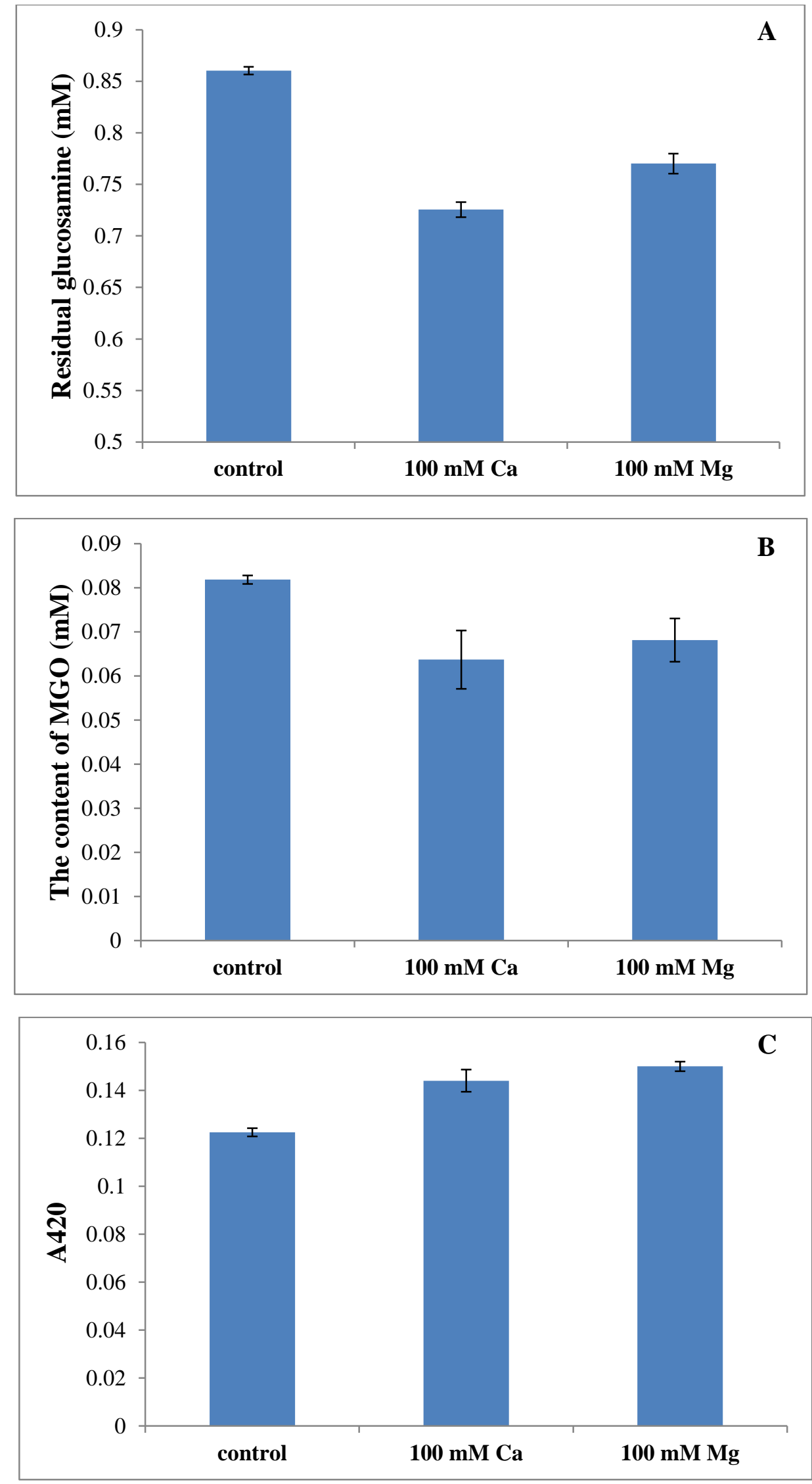

Figure 4 


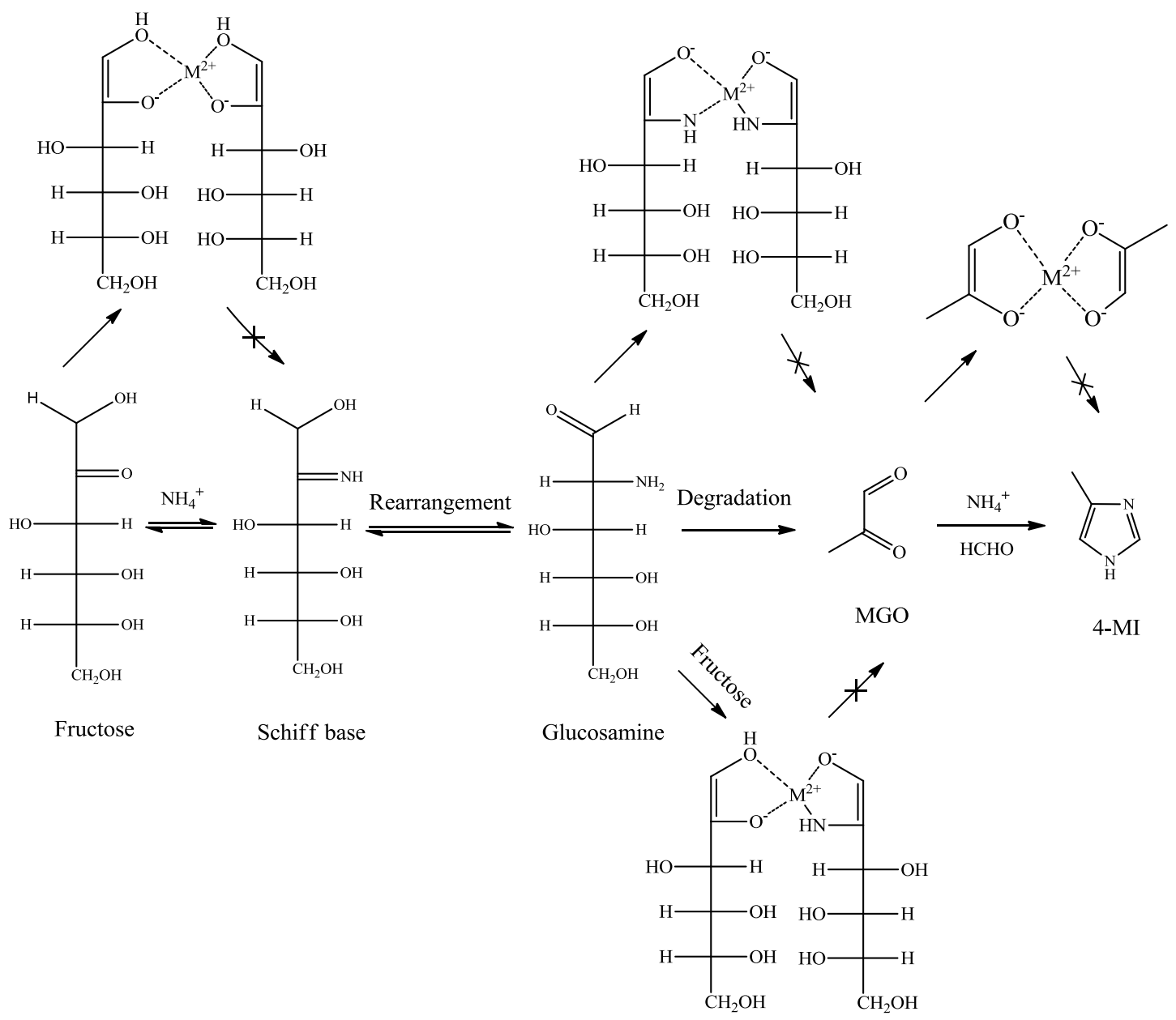

Figure 5 


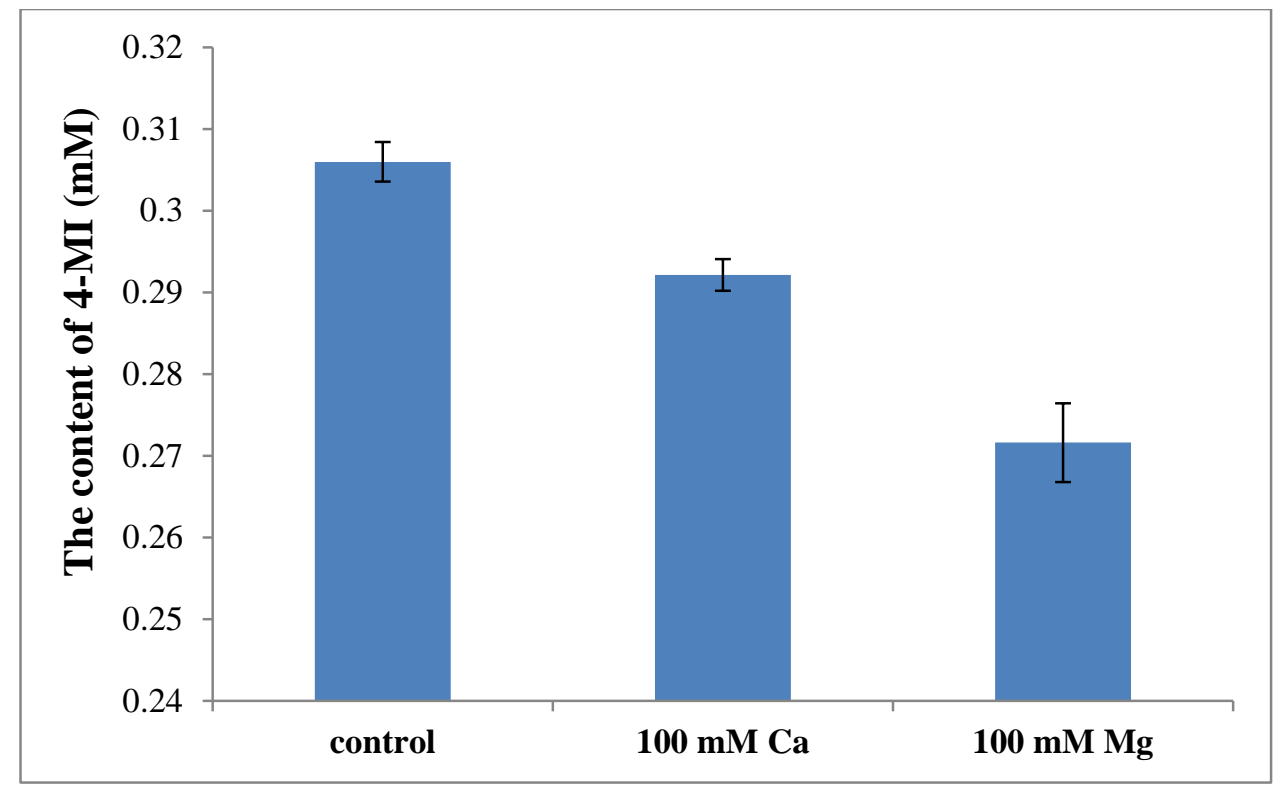

Figure 6 